\title{
Porphyrin Measurement
}

National Cancer Institute

\section{Source}

National Cancer Institute. Porphyrin Measurement. NCI Thesaurus. Code C120648.

The determination of the porphyrin present in a sample. 